\title{
EFFICACY OF BEHAVIOURAL GRADED ACTIVITY COMPARED WITH CONVENTIONAL EXERCISE THERAPY IN CHRONIC NON- SPECIFIC LOW BACK PAIN: IMPLICATION FOR DIRECT HEALTH CARE COST
}

\author{
A. I. BELLO ${ }^{1}$, J.N.A. QUARTEY ${ }^{1}$ and M. LARTEY ${ }^{2}$ \\ ${ }^{1}$ Department of Physiotherapy, School of Biomedical and Allied Health Sciences, University of Ghana, \\ ${ }^{2}$ Department of Medicine, School of Medicine and Dentistry, University of Ghana.
}

DOI: http://dx.doi.org/10.4314/gmj.v49i3.8

Corresponding Author: Dr. Ajediran I. Bello

E-mail:badmus@chs.edu.gh

Conflict of Interest: None declared

\section{SUMMARY}

Background: The relative efficacy of conventional exercise therapy (CET) and behavioural graded activity (BGA) has not been fully established to inform the preference in clinical practice.

Objective: To compare CET and BGA on the treatment outcome of chronic non-specific low back pain (LBP).

Methodology: Participants were assigned into either BGA or CET group in this randomized feasibility intervention. The CET group received supervised exercise therapy while BGA group engaged in individually prescribed sub-maximal activities based on timecontingent principles. Interventions were carried out twice weekly and over a period of 12 weeks. Outcome measures were numerical rating scale and RAND 36item health survey which were administered at baseline, week 4 and week 12 . Health care cost questionnaire was also administered to evaluate physiotherapy cost after 12 weeks. Mixed design two-way ANOVA with level of significance set as priori at $p<0.05$ was used to compare both groups.

Results: Seventy-seven and half percent (62) participants $(\mathrm{CET}=29$ and $\mathrm{BGA}=33)$ with mean ages $45.0 \pm 12.2$ and $43.1 \pm 13.2$ years respectively, completed the study. Both groups improved significantly $(p<0.001)$ during the intervention. However, there were no significant differences $(p>0.05)$ between the treatment groups at any time points and for any measures assessed. Therapeutic benefits in both groups have bearing on direct health care costs.

Conclusion: The results indicate that CET and BGA have similar outcomes in patients with chronic nonspecific LBP with regard to the pain and quality of life. Effective application may however be hampered by the cost-related factors thus suggesting evaluation of health care system in Ghana.
Key words: Pain; Cognitive Therapy; Exercise Therapy; Quality of life; direct costs

\section{INTRODUCTION}

Low back pain is one of the most common reasons for seeking medical care and it imposes a significant burden on individuals and society at large. ${ }^{1}$ Approximately, $10 \%$ to $20 \%$ of patients with low back pain develop chronic low back pain (CLBP), defined as pain and disability persisting for more than 12 weeks. ${ }^{2}$ Chronic non-specific low back pain (LBP) therefore refers to pain present in the lumbo-sacral area for at least 12 consecutive weeks without any specific link to a pathology. $3,4,5$

It is prevalent in many countries around the world. ${ }^{6}$ Epidemiological data indicate a point prevalence ranging from 19 to $27 \%$ and a lifetime prevalence of about $60 \%{ }^{7}$ Although such surveillance data on CLBP are not common in Ghana, a reported prevalence of $67 \%$ was found among male underground miners in Obuasi Mines, over a 12-month period, with 76\% (142) of the miners obtained sick leave for a mean duration of six days within the same period owing to the pain syndrome. ${ }^{8}$

The self-limiting and resistant nature of CLBP has compelled the sufferers to be increasingly skeptical about the growing list of treatment approaches commonly promoted as the panacea to their problems. This scenario often generates frustration among the patients, the clinicians and other stakeholders. There is indeed abundant evidence suggesting the benefits of therapeutic exercise on pain and disability in patients with chronic non-specific LBP. $9,10,11,12$

In spite of the therapeutic gains from exercises, findings from a systematic review concluded that the most effective mode of exercise therapy remain debatable. ${ }^{11}$ 
This conclusion has stimulated scientific curiosity to evaluate the relative efficacy of the modes of exercise therapy in physiotherapy practice. Obviously, the need to provide high quality and efficient health care to the patients is premised on the continuous evaluation of available modalities and/or treatment approaches for relative efficacy and cost effectiveness.

A growing body of epidemiological evidence has implicated physical activity and a variety of psychological risk factors as being important to the genesis of CLBP. ${ }^{13}$ Thus, cognitive behavioural therapies have been documented to be useful in modifying health behaviours and risk factors through targeted action on beliefs and positive coping strategies. Studies about the relative efficacy of the supervised exercise therapy and cognitive behavioural therapy for alleviation of CLBP have also been well reported. ${ }^{14,15,5}$

In reality, the extrapolation of the results of such studies into African society is difficult considering the diverse differences in culture as regards pain perception and belief, nature and organization of the health care. Considering the pessimism surrounding the prognosis of CLBP, the present design is necessitated to complement the existing knowledge on the topic within African context. In addition, the impact of CLBP is usually estimated by evaluating the costs of its management with respect to the socio-economic background of the patients. Cost-related studies on back pain are well documented in literature for developed countries; such studies are not readily available for reference in developing nations including Ghana.

Health care cost is broadly divided into direct and indirect costs. Direct health care costs refer majorly to those costs involving monetary exchange with respect to payment for diagnosis, treatment, continuing care, prevention, rehabilitation and organization but also include costs incurred for goods and services consumed directly because of illness which are not health care related. ${ }^{16,17}$ Indirect costs on the other hand, are those reflecting the economic value of consequences for which there is no direct monetary transfer.

The management of CLBP places resource-intensive demands on health care system particularly in developing countries where health care facilities are already over-stretched. Given the variations in the social welfare and insurance system between countries, the present study poised to assess the outcome of behavioural graded activity compared to conventional therapy in patients with chronic non-specific LBP with respect to the costs implication in Ghana.
We hypothesized that conventional exercise therapy would be more efficacious than the behavioural graded activity as regards the treatment outcomes of chronic non-specific LBP.

\section{MATERIALS AND METHOD}

\section{Study design}

A feasibility intervention design was adopted in this study in which participants were assigned to two modes of intervention simultaneously with the aim of determining whether an intervention should be recommended for efficacy testing.

\section{Study Area}

The study took place at the Out-Patient Units of Physiotherapy Departments of Ridge Hospital in the Accra Metropolis, Orthopaedic Training Center Nsawam and St. Joseph's Catholic Hospital, Koforidua. The OutPatient physiotherapy Unit of Ridge Hospital is an ultramodern physiotherapy facility established to provide medical rehabilitation service to patients presented with diverse musculoskeletal and neuromuscular dysfunctions across all ages within and beyond the Accra Metropolis.

The Orthopaedic Training Center Nsawam is a rehabilitation centre established by the Divine Word Missionaries to train rehabilitation technicians for rural communities and to cater for people with various impairments and disabilities. The center ensures comprehensive health care through the design and provision of orthopaedic appliances for patients' ambulation or function. It largely operates on out-patient basis.

The Out-Patient Physiotherapy Unit of the St. Joseph's Catholic Hospital, Koforidua also manage patients with orthopeadic cases including back pain, joint arthroplasy and various forms of disability. The Hospital receives external support from various Non-Governmental Agents to boost its operation in all the departments. The three health care facilities are located in the Eastern and Greater Accra Regions of Ghana.

\section{Study population/participants}

Eighty (80) patients diagnosed with chronic nonspecific LBP were invited to participate in this study. They were eligible for the study if they were; referred for physiotherapy by resident orthopaedic specialists at three selected health facilities; aged between 18 and 65 years; had suffered low back pain for at least three months; score at least $4 / 10$ on numerical pain rating scale. Patients with Low back pain of specific pathology; those who had received physical or manual therapy during the previous 6 months and those with chronic disease were excluded from the study. 


\section{Sample size and sampling procedure}

The sample size for this study was estimated based on clinically important improvements in patients' measures through anchor-based approach which was set at $\geq 30 \%$. ${ }^{18}$ This target was expected after completion of both treatments (i.e. after 12 weeks) and it was considered to be clinically relevant; 80 participants were needed to detect this difference. In this regard, statistical power was considered to be $1-\beta(80 \%)$. Thus, the inclusion of at least 40 patients per group was planned. $^{19}$

Participants were assigned to either behavioural graded activity (BGA) group or conventional exercise therapy (CET) group by an independent person through ballot without replacement. They were equally allocated to either group by allowing them to pick an option (BGA or CET) from a sealed brown envelop containing 40 of the either option. Patients were blinded to treatment allocation, although they were informed about receiving exercise therapy without revealing the content of the treatment to them. All the participating physiotherapists were not blinded to treatment allocation but did not take part in the outcome measurements. The contrasts between the two groups were maintained by separating them throughout the study period.

\section{Data collection}

Data were collected from May, 2013 to January, 2014 concurrently at the selected health care facilities.

\section{Materials for data collection}

The pain intensity was assessed using numerical rating scale, an 11-point scale from which patients selected the number most representative of their average pain intensity over the last one-week. A higher score indicates severe pain i.e. Zero (0) represents no pain while Ten (10) represents worst pain. ${ }^{14}$ The quality of life of the patients was assessed with RAND 36-item Health Survey on 8 domains as follows: physical functioning, role limitations due to physical and emotional functioning's, Energy/fatigue, bodily pain, general health perception, social functioning and emotional wellbeing. ${ }^{20}$

Each domain is scored on a range of 0 to 100 and higher scores indicate favourable health outcome of individuals. The direct cost of physiotherapy was evaluated using a self-designed Health care cost questionnaire. It consists of two sections (A \& B). Section A comprised information about socio-demographic and socioeconomic profiles of the participants and Section B was concerned with direct health care costs with regard to the hospital expenses. The questionnaire was found to be reliable on test-retest evaluation $(\mathrm{r}=0.87)$.

\section{Ethical considerations}

Approval for this study was sought and obtained from the Ethical and Protocol Review Committee of the University of Ghana Medical School. Written informed consent was obtained from the patients after explaining the information regarding the research procedure. Researchers adhered strictly to the ethical principles on human studies as contained in the Helsinki declaration for human and animal researches.

\section{Intervention}

The participating physiotherapists in both groups were invited separately to a four-day interactive sessions to design standardized exercise programme (CET group) and the prescribed sub-maximal activity participation based on time-contingent method (BGA group). Both interventions were carried out on out-patient setting, twice weekly for 45 minutes and each treatment approach lasted for a period of 12 weeks. The baseline patient's pain intensity and quality of life were assessed using numerical rating scale and RAND 36-item Health Survey respectively. Assessment was performed by independent assessor who was blinded to the allocation of the patients.

\section{Conventional exercise therapy group}

The CET group received supervised exercises programme from a broad spectrum of therapeutic exercises. The content of the CET was decided by consensus among the participating physiotherapists and reflects usual care. Detail of the exercise programme is presented in Table 1. The physiotherapists were also allowed to use other supportive techniques such as lumbar traction, massage as well as non-manipulative techniques e.g. McKenzie. The use of manipulative therapy, electrotherapy and specialized techniques such as electro-acupuncture were however excluded.

\section{Behavioural Graded Activity Group}

The treatment approach in BGA involved an individual, sub-maximal, gradually increased performance of activities in the form of exercises but specific to the patients' limitation using an operant-conditioning behavioural approach. This was premised on the patients' major baseline complaints. Physiotherapist-patients interaction was established to identify patients' tolerance level in specific activities. Baseline trials of activities were jointly determined. Patients' belief about pain was discussed using pain model. Exercise chart was also provided for self-care purpose. Goals were formulated to serve as references. The treatment principle was guided by the patient's feedback with respect to functional abilities. Quotas were set for frequencies, loads, repetitions, and duration for each activity together with the patients. The treatment step wise approach is described in Table 2 
Table 1 Exercise programme designed for the Conventional Exercise Therapy

\begin{tabular}{|c|c|c|}
\hline Exercise & Description & Sets/Repetition/Duration \\
\hline Stretching & $\begin{array}{l}\text { Stretching of the abdominal muscles through repeated trunk extension in erect } \\
\text { standing position. } \\
\text { Stretching of the hamstring muscles with the patients in supine lying while } \\
\text { the physiotherapist flexes the hip at } 90^{\circ} \text { and passively extend the ipsilateral } \\
\text { knee. } \\
\text { Global stretching of the trunk and back muscles with the patients sitting on } \\
\text { heels, flexed trunk with the abdomen resting on the anterior aspect of both } \\
\text { thighs. }\end{array}$ & $\begin{array}{l}3 \text { sets of } 5 \text { repetitions for } 30 \text { seconds } \\
3 \text { sets of } 10 \text { repetitions for } 30 \text { seconds } \\
3 \text { sets of } 10 \text { repetitions for } 30 \text { seconds }\end{array}$ \\
\hline Strengthening & $\begin{array}{l}\text { Abdominal curl; with patients in supine lying, flexed both knees and supports } \\
\text { the head with both hands around the occiput. Patients then actively lift the } \\
\text { trunk and head simultaneously. } \\
\text { Back extensors; with the patients in prone lying and both upper limbs by the } \\
\text { sides, active back and trunk extension is performed. }\end{array}$ & $\begin{array}{l}2 \text { sets of } 5 \text { repetitions subject to modification } \\
\text { as the treatment progresses } \\
3 \text { sets of } 5 \text { repetitions subject to modification } \\
\text { as the treatment progresses }\end{array}$ \\
\hline Mobilization & $\begin{array}{l}\text { Extension; physiotherapist positioned the patients in an inclined prone lying } \\
\text { by raising the head of the plinth while the he passively mobilizes the patients } \\
\text { back. Flexion mobilization was performed with patients in supine lying with } \\
\text { the knees flexed while the patient passively flexes both hips with his hands. }\end{array}$ & 3 sets of 10 repeatitions \\
\hline Stabilization & $\begin{array}{l}\text { For the abdominals, back, pelvic and lower limb muscles. Patient in prone } \\
\text { leaning (four-point-kneeling) raises the contra- lateral lower and upper limbs } \\
\text { off the floor. } \\
\text { Auto-resisted hip flexion with patients in supine lying position resist the hip } \\
\text { flexion with the contra-lateral upper limb }\end{array}$ & $\begin{array}{l}3 \text { sets of } 10 \text { repeatitions for } 1 \text { minute, subject } \\
\text { to modification as the treatment progresses. }\end{array}$ \\
\hline
\end{tabular}

Table 2 Description of the treatment approach in behavioural graded activity group

\begin{tabular}{|l|l|l|}
\hline Exercise & Description & Sets/Repeatition/Duration \\
\hline Aerobic training phase & $\begin{array}{l}\text { Warm up exercise with bicycle ergometer set at 0-5 Watts } \\
\text { Intensity of training increased to 10 Watts after warm up (sub- } \\
\text { maximal training at 70-80\% maximum heart rate). } \\
\text { Cool down exercise was performed with gradual reduction in } \\
\text { the speed. }\end{array}$ & 3 minutes \\
20 minutes \\
\hline Strengthening of lower limbs & $\begin{array}{l}\text { Quads drills and harmstring curls were performed on quadri- } \\
\text { ceps chair in normal sitting position with varying resistances. } \\
\text { Wall sliding exercise (Squatting) }\end{array}$ & 3 sets of 10 repetitions \\
\hline $\begin{array}{l}\text { Paraspinal muscle strengthen- } \\
\text { ing }\end{array}$ & $\begin{array}{l}\text { Active trunk extension in prone lying position and abdominal } \\
\text { curls in supine position were performed. }\end{array}$ & 30 seconds at series of intervals \\
\hline Generalization phase & $\begin{array}{l}\text { Prevention and self-management of relapses through back cares } \\
\text { education at week 10, 11 and 12. }\end{array}$ & 10 minutes \\
\hline
\end{tabular}

\section{Treatment outcome evaluation}

Repeated assessments were performed for both groups on pain intensity and quality of life at weeks 4,8 and 12. Follow up assessment was carried out at weeks 16 for pain intensity only. The direct health care costs (including physiotherapy) incurred by the patients were evaluated at the end of the intervention. Participants were requested to complete the health care cost questionnaire to summate the actual and associated costs in the cause of the treatment. The total cost was estimated partly by the multiplication of the number of physiotherapy sessions with the financial expenditure per visit.

\section{Data and statistical analysis}

Analysis was performed with intention-to-treat principle using SPSS version 19 statistical software.
Descriptive statistics of mean, standard deviation and percentage were used to summarize sociodemographic, socio-economic data, clinical attributes of the patients and direct health care cost for chronic low back pain. The effects of continuous outcomes (means with 95\% CI) were expressed between baseline and week 4; week 8; week 12 and the follow up assessment outcomes.

The minimal clinically important differences (MCIDs) within and between groups comparisons were defined as $\geq 30 \%$ for all the measures. Comparison of preintervention parameters of the two groups was determined using two sample unpaired t-test whilst mixed design 2-way ANOVA was used to determine the difference between the two groups on the selected measures. 
For all the comparisons, a $\rho$-value of 0.05 (two-tailed) was considered to indicate statistical significance at $95 \%$ CI.

\section{RESULTS}

Socio-demographic and socio-economic profiles of the participants

Eighty(80) patients with chronic non-specific LBP were enrolled to participate in this study. However, $77.5 \%$ (62) of the patients (29 in CET and 33 in BGA) were able to complete while $22.5 \%$ (18) could not be considered for analysis on the account of poor adherence to treatment regimens, inherent challenges with finance and instances of discontinuity with the treatment.

The mean age of the participants in the CET group was $45.0 \pm 12.2$ years compared to $43.1 \pm 13.2$ years in the BGA group. The age range of the participants in both groups was 20-72 years. Majority of the participants in BGA were males, $60.2 \%$ (20) while the CET comprised more female participants, 62.1\% (18). Most patients had experienced LBP between 6 and 24 months in both groups. $34.5 \%$ (10) and $36.4 \%$ (12) of the participants in conventional and behavioural groups respectively, had tertiary education.

Thirty-Four and half percent (10) and 36.4\% (12) of the patients in CET and BGA groups respectively earned monthly income above GHC501.00 monthly as against the respective $10.3 \%$ (3) and $12.1 \%$ (4) who earned less than GHC100.00 per month. Most participants in both groups either engaged in paid job or were self-employed as shown in Table 3.

Table 3 Socio-economic profile of the participants

\begin{tabular}{|l|l|l|l|l|}
\hline & $\begin{array}{l}\text { Convention- } \\
\text { al(n=29) } \\
\text { Frequency }\end{array}$ & $\%$ & $\begin{array}{l}\text { Behaviour- } \\
\text { al (n=33) } \\
\text { Frequency }\end{array}$ & $\%$ \\
\hline & & & & \\
\hline Income source & & & & \\
\hline Support & 6 & $20.7 \%$ & 1 & $3.0 \%$ \\
\hline Below 100 GH $\phi)$ & 3 & $10.3 \%$ & 4 & $12.1 \%$ \\
\hline $101-300 \mathrm{GH} \phi)$ & 5 & $17.2 \%$ & 8 & $24.2 \%$ \\
\hline $301-500 \mathrm{GH} \phi)$ & 5 & $17.2 \%$ & 8 & $24.2 \%$ \\
\hline Above 501 GH $\phi)$ & 10 & $34.5 \%$ & 12 & $36.4 \%$ \\
\hline Occupation & & & & \\
\hline Paid Job & 10 & $13.8 \%$ & 12 & $36.4 \%$ \\
\hline Self-Employed & 10 & $34.5 \%$ & 12 & $36.4 \%$ \\
\hline Unemployed & 5 & $34.5 \%$ & 3 & $9.1 \%$ \\
\hline Retired & 4 & $17.2 \%$ & 6 & $18.2 \%$ \\
\hline
\end{tabular}

Comparison of CET and BGA groups for pain and quality of life at baseline

Comparison of CET and BGA groups on numerical rating scale (NRS) and the components of SF-36 QoL questionnaire show no significant differences $(\mathrm{p}>0.05)$ between the two groups at baseline. There was a clini- cal homogeneity between the two groups which implies that findings from each group after the 12-week intervention largely reflect the relative efficacy of both treatment techniques. However, the BGA group scored higher $(p=0.038)$ than the conventional group on the pain component of SF-36 QoL. In addition, within group comparison using repeated measure ANOVA showed significant improvements $(p<0.001)$ for both groups over the baseline scores through to the end treatment in all the main measures.

Comparative efficacy of CET and BGA on pain and quality of life among the participants

Between group comparison using mixed design 2-way ANOVA showed no differences $(p>0.05)$ for the main and interaction effects on the outcomes measures after 12 weeks of intervention. The group treatment (main) and weeks of intervention (interaction) effects of CET were not superior to that of BGA (Table 4).

Table 4 Comparative efficacy of CET and BGA on the participants' pain and quality of life with Linear mixed model analysis

\begin{tabular}{|c|c|c|c|c|c|}
\hline Measures & $\begin{array}{l}\text { Type III sum } \\
\text { of mean } \\
\text { square }\end{array}$ & $\begin{array}{l}\text { Mean } \\
\text { Square }\end{array}$ & $\mathrm{df}$ & $\mathrm{f}$ & $\rho$ \\
\hline $\begin{array}{l}\text { Numerical Rating } \\
\text { Scale Week * Group } \\
\text { Error }\end{array}$ & $\begin{array}{l}2.57 \\
321.39 \\
\end{array}$ & $\begin{array}{l}0.643 \\
0.643 \\
\end{array}$ & $\begin{array}{l}4 \\
300\end{array}$ & 0.600 & 0.663 \\
\hline $\begin{array}{l}\text { Physical Functioning } \\
\text { Week * Group } \\
\text { Error }\end{array}$ & $\begin{array}{l}1286.88 \\
158311.50\end{array}$ & $\begin{array}{l}428.96 \\
659.63\end{array}$ & $\begin{array}{l}3 \\
240\end{array}$ & 0.650 & 0.583 \\
\hline $\begin{array}{l}\text { Limitations due to } \\
\text { Physical Health } \\
\text { Week * Group } \\
\text { Error }\end{array}$ & $\begin{array}{l}1636.43 \\
357904.91\end{array}$ & $\begin{array}{l}545.47 \\
1491.27\end{array}$ & $\begin{array}{l}3 \\
240\end{array}$ & 0.366 & 0.778 \\
\hline $\begin{array}{l}\text { Limitations due to } \\
\text { emotions } \\
\text { Week * Group } \\
\text { Error } \\
\end{array}$ & $\begin{array}{l}17287.37 \\
1199297.24\end{array}$ & $\begin{array}{l}5762.45 \\
4997.07\end{array}$ & $\begin{array}{l}3 \\
240\end{array}$ & 1.153 & 0.328 \\
\hline $\begin{array}{l}\text { Energy/Fatigue } \\
\text { Week * Group } \\
\text { Error }\end{array}$ & $\begin{array}{l}808.04 \\
86050.55\end{array}$ & $\begin{array}{l}269.34 \\
358.54 \\
\end{array}$ & $\begin{array}{l}3 \\
240 \\
\end{array}$ & 0.751 & 0.523 \\
\hline $\begin{array}{l}\text { Emotional well-being } \\
\text { Week * Group } \\
\text { Error }\end{array}$ & $\begin{array}{l}571.57 \\
100819.21\end{array}$ & $\begin{array}{l}190.5 \\
420.08 \\
\end{array}$ & $\begin{array}{l}3 \\
240 \\
\end{array}$ & 0.454 & 0.715 \\
\hline $\begin{array}{l}\text { Social Functioning } \\
\text { Week * Group } \\
\text { Error }\end{array}$ & $\begin{array}{l}921.88 \\
105397.24\end{array}$ & $\begin{array}{l}307.29 \\
439.15\end{array}$ & $\begin{array}{l}3 \\
240\end{array}$ & 0.700 & 0.553 \\
\hline $\begin{array}{l}\text { Bodily Pain } \\
\text { Week * Group } \\
\text { Error }\end{array}$ & $\begin{array}{l}1539.99 \\
113126.81\end{array}$ & $\begin{array}{l}513.33 \\
471.36\end{array}$ & $\begin{array}{l}3 \\
240\end{array}$ & 1.089 & 0.354 \\
\hline $\begin{array}{l}\text { General Health } \\
\text { Week * Group } \\
\text { Error }\end{array}$ & $\begin{array}{l}471.97 \\
1024506.25\end{array}$ & $\begin{array}{l}157.32 \\
444.05\end{array}$ & $\begin{array}{l}3 \\
240\end{array}$ & 0.354 & 0.786 \\
\hline
\end{tabular}

\section{Health care cost incurred by the participants}

For the costs incurred, $96.6 \%$ (28) of the patients in CET group and $87.9 \%$ (29) in BGA group purchased drugs to supplement their treatments for LBP. 
Patient in the CET group spent the mean sum of GHC29.4 \pm 17.7 per visit as compared to GHC24.1 \pm 40.8 spent by patient in BGA (Table 5 ).

Table 5 Health care costs incurred by the participants in Ghana Cedis $(\mathrm{GH} \phi)$

\begin{tabular}{|l|l|l|l|l|}
\hline Cost & $\begin{array}{l}\text { CET } \\
(\mathrm{n}=29) \\
\text { Frequency }\end{array}$ & $\%$ & $\begin{array}{l}\text { BGA } \\
(\mathrm{n}=33) \\
\text { Frequency }\end{array}$ & $\%$ \\
\hline Drug purchase & 28 & 96.6 & 29 & 87.9 \\
$\begin{array}{l}\text { Yes } \\
\text { No }\end{array}$ & 11 & 3.4 & 4 & 12.1 \\
\hline Payment per visit & & & & \\
\hline NHIS & 13 & 44.8 & 12 & $36.4 \%$ \\
\hline Cash & 16 & 55.2 & 21 & $63.6 \%$ \\
\hline Costs (GH $\dot{ }))$ & Mean & SD & Mean & SD \\
Amount/person/visit & 29.4 & 17.7 & 24.1 & 40.8 \\
Number of visits & 24 & & 24 & \\
Cost per person & 705.6 & & 578.4 & \\
\hline
\end{tabular}

\section{DISCUSSION}

Two published treatment models that are well documented in literature are applicable in physiotherapy practice. ${ }^{14}$ Biomedical model recognizes pain as a sign of physiological damages and the treatment is directed towards alleviating the pathologic condition in order to abate or alleviate the pain. The therapeutic benefits of exercise are premised on this model. The principles of biopsychosocial model on the other hand, are based on the view that maladaptive behaviours are learnt, thus it can be modified through new learning experiences. ${ }^{21}$

Application of BGA is deeply rooted in this model. Even though both approaches have been proven to be effective, debate is ongoing about their relative efficacy. The high rate of relapses of LBP indeed calls for the need to develop self-management skills in patients with this condition to curtail its burdens. The main focus of this study therefore was to determine the relative efficacy of the two treatment approaches in the treatment of chronic non-specific LBP with regard to the pain and quality of life among the sufferers.

At the end of the 12-week interventions, patients in both groups reported similar experience. We therefore reject our initial hypothesis that CET would be more efficacious than the BGA in the treatment of patients with chronic nonspecific LBP. Also, in view of the grossly under-reported cost-related studies in Africa, the costs implication on the part of the participants was considered.

The mean age of the participants in this study conforms to the mean age of the work force in Ghana and majority of them were either engaging in monthly paid job or were self-employed. This finding confirms the high prevalence of chronic low back pain as reported in the previous study. ${ }^{8}$ The participants have experienced low back pain for a period of 6 to 24 months thereby justifying the chronicity of the presented low back pain syndrome, defined as presentation of pain for at least 12 consecutive weeks. ${ }^{2}$ Most of the sampled participants in this study were moderately educated which explained their occupational status and the modest sources of income.

A strong tie has been identified between low socioeconomic profile and high mortality cum morbidity from many chronic conditions including musculoskeletal disorders. Occupation and income are the two surrogate measures of socio-economic status that are usually affected by chronic conditions particularly at adult life. ${ }^{22}$ Scientific evidence has lent credence to the hypothesis that less well educated people are more likely to be affected by disabling back pain. Granted that the participants in this study are moderately educated, the underlying socio-economic profile could be regarded as the chief predisposing factors for the incidence of low back pain.

Participants within each group improved significantly with respect to pain and their quality of life as the treatments progressed from the baseline. However, there was no statistical significant difference between the two groups on all the measures. Admitted that the evaluation of the treatment outcome is on short term basis in this study, the present findings follow the same trend as found in the reports of Macedo et al. ${ }^{23}$ The improvements emanating from the two approaches further buttress the established efficacies exercise in the management of CLBP and this is in agreement with the existing reports.

For instance, Vonk et al reported comparable effectiveness of conventional exercise therapy and BGA on pain severity, patients' complaints and functional status following 10 -week intervention. ${ }^{14}$ Systematic review by Macedo et al also reported that, graded activity in the short and intermediate terms is slightly more effective than a minimal intervention but not more effective than other forms of exercise for persistent LBP. ${ }^{23}$

Exercise interventions that modify physical stress have been shown to decrease impairments, functional limitations, disability, and pain in a variety of patient populations by influencing the dysfunctional descending paininhibitory mechanism. ${ }^{24,25}$ Thus, gradually increasing physical activity presupposes that pain and disability would reduce thereby ensuring positive rehabilitation outcome for patients with chronic pain. 
In addition, enhanced physical activity could positively influence cognitions, emotions and thoughts, hence the improved outcome on the components of RAND 36-SF for the participants. ${ }^{26}$

The aim of BGA, on the other hand is not to directly address the physiological component of CLBP but to modify one of the three response systems i.e. behavioural, cognition and physiological reactivity.

Behaviour changes are initiated by the therapists by helping patients to confront and change their maladaptive behavior/thoughts thereby adopting better coping strategy which can lead to a decrease in distress and eventual reduction in the pain experience to some extent. ${ }^{27}$ The underlying basic principles contribute to the significant improvement in the overall quality of life of the participants in this group. It thus follows that either approach could be used in the management of CLBP.

Meanwhile, in spite of the modest sources of income among the patients, the costs of physiotherapy per visit were GH $\notin 29.4$ and GH $\notin 24.1$ for CET and BGA respectively. These cover transportation, medication (topical) and fee-for-physiotherapy service on out-patient basis at the selected health facilities. Only 40.3\% (25) out of the total participants (62) registered with the National Health Insurance Scheme (NHIS).

Although, the introduction of NHIS is aimed primarily at addressing the financial burden of health care for all, physiotherapy has not yet been fully incorporated into the scheme". It is already known that the primary health care system in Africa is still inadequate and indeed has not fully considered rehabilitation as parts of its components thus creating gap in the process. This development is impacting negatively on our specialist care facilities that have to cope with large numbers of people who require non-specialist interventions. To our knowledge, the present trial is the first of its kind and represents a marginal fraction of cost of illness.

This study is limited by the following factors: firstly, the few measures used as treatment outcomes might have limited the therapeutic manifestations of both interventions. Secondly, follow up evaluation after expiration of the intervention was not carried out due to decline compliances on the part of the participants. This would have depicted the extent of the potency of the treatment effects. Extension of this study beyond feasibility design may provide more useful information from this intervention. Lastly, the documentation about the costs is still grossly inadequate but the present findings could start as a starting point to stimulate research interests in health care costs in Ghana.

\section{CONCLUSION}

In conclusion, conventional exercise therapy and behavioural graded activity are equally effective in reducing pain and improving quality of life in patients with non-specific chronic low back pain on short term basis. This implies that either approach could be used in clinical situation. The patient's incurred expenses to receive remedy for this condition potentially add to the list of burdens associated with CLBP.

\section{RECOMMENDATION}

The therapeutic benefits accrued from the two interventions do not preclude the financial burden being borne by the patients with chronic non-specific LBP. There is the need therefore to evaluate the system-related factors (e.g. Funding) in the health care system with a view to ensure effective health care delivery.

\section{ACKNOWLEDGEMENT}

The pilot project was fully sponsored by the University of Ghana-Danish Universities academic partnership for Building Stronger Universities Initiative Platform on Human Health (BSU-PHH).

\section{REFERENCE}

1. Penstri P, Janwantanakul P. Effectiveness of brief education combined with home-based exercise programme on pain and disability of office workers with chronic low back pain: A pilot study. $J$ Phys Ther Sci. 2012; 24: 217-222.

2. Maher CG. Effective physical treatment for chronic low back pain. Orthop Clin North Am. 2004; 35: 57-64

3. Bekkering GE, Hendricks HJM, Koes BW, Oostendorp RAB, Ostelo RWJG,Thomanssen JMC et al. National practice guidelines for physical therapy in patients with low back pain. Royal Dutch Society for physical therapy-guidelines for physical therapy in patients with low back pain. 2003; page 1-29.

4. David GE, Mehrdad R, Ghasemi M, Hassan-Zadeh H, Sotoodeh-Manesh A, Pouryaghoub G. In chronic low back pain, low level laser therapy combined with exercise is more beneficial than exercise alone in the long term: a randomized trial. Aust $J$ Physiother. 2007; 52: 155-160.

5. Magalhaes MO, Renovato FJ, Franca FJR, Burke TN, Ramos LAV, e Silva AP, et al. Efficacy of Graded Activity Versurs Supervised Exercises in Patients with Chronic Non-Specific Low Back Pain: Protocol of a Randomized Controlled Trial, BMC Musculoskelet Disords. 2013; 14:36

6. Taylor A., and Werner R. (2005): Prevention of low back pain and disability. In Back pain. Haig 
JA\& Colwell M (eds). American College of Physicians. Philladephia. Pg 419-430.

7. Demoulin C. Marty M. Genevay S. Vanderthommen M. Mahieu G, Henrotin Y. Effectiveness of preventive back educational interventions for low back pain: a critical review of randomized controlled clinical trials. Eur Spine J. 2012; 21: 2520 2530

8. Bio FY, Sadhra S, Jackson C Burge PS. Low back pain in underground gold miners in Ghana. Ghana Med J. 2007; 41(1): 21-25.

9. Smidt N, de Vet HCW, Bouter LM and Dekker. Effectiveness of exercise therapy: A best-evidence summary of systematic reviews. Aust J Physiother, 51. 2005; 71-85.

10. Ferriara ML, Smeets RJ, Kamper SJ. Can we explain the heterogeneity among randomized clinical controlled trials? Phys Ther. 2010; 90: 1383-1403.

11. Oesch P, Kool J, Hagen K.B. et al. Effectiveness of exercise on work disability in patients with nonacute non-specific low back pain: Systematic review and meta-analysis of randomized controlled trials. J Rehabil Med Suppl. 2010; 42; 193-205.

12. Smith C, Grimmers-Somers K. The treatment effects of exercise programmes for chronic low back pain. J Eval Clin Pract. 2010; 16: 484-491.

13. Huijnen IPJ, Verbunt JA, Peters ML. Differences in activity-related behaviour among patients with chronic low back pain. Eur J Pain. 2011; 15: 748755.

14. Vonk F, Verhagen AP, Geilen M, Vos CG, Koes BM. Effectiveness of behavioural graded activities compared with physiotherapy treatment in the chronic neck pain: Design of randomized clinical trials. BMC Musculoskelet Disords. 2004; 5: 334.

15. Macedo LG, Smeets RJEM, Maher CG, Latimer J, McAuley JH. Graded Activity and Graded Exposure for Persistent Nonspecific Low Back Pain: A Systematic Review. Phys. Ther. 2010; 90:860879.

16. van Tulder MW, Koes BW, Bouter LM. A Costof-illness Study of Back Pain in Netherlands. Pain. 1995; 62: 233-240.

17. Dagenais S, Caro J, Haldeman S. A Systematic Review of Low Back Pain Cost of Illness Studies in the United States and internationally. Spine J. 2008; 8: 8-20.

18. Farray JT, Young JP, LaMoreaux L, Werth JL, Poole, RM. Clinical importance of changes in chronic pain intensity measured on an 11-point numerical pain rating scale. Pain. 2001; 94; 149158.

19. Eng, J. Sample size estimation: How many individuals should be studied? Radiology. 2003; 227: 309-313.

20. De Visser CL, Bilo HJG, Groenier KH, de Visser $\mathrm{W}$, Meyboom-de Jong. The Influence of cardiovascular disease on quality of Life in type-2 diabetics. Qual Life Res. 11: 249-261, 2002.

21. Linton SJ. Chronic back pain: Integrating psychological and physical therapy-An overview. J. Behav. Med. 1994; 20: 101-104.

22. Dionne CE, von Korff M, Koepsell TD, Deyo RA, Barlow WE, Checkoway H. Formal Education and Pain: a review. Epidemiol Community Health. 2001; 55: 455-468.

23. Macedo LG, Lartimer J, Maher CJ, Hodges PW, McAuley JH, Stanton MK, Stafford R. Effect of Motor Control Exercises Versus Graded Activity in Patients With Chronic Nonspecific Low Back Pain: A Randomized Controlled Trial. Phys Ther 2012; 92:363-377.

24. Mueller MJ., Maluf KS. Tissue adaptation to physical stress: a proposed "physical stress theory" to guide physical therapist practice, education, and research. Phys Ther. 2002; 82:383-403.

25. van Middelkoop M., Rubinstein SM, van Tulder MW. A Systematic Review on the effectiveness of physical and rehabilitation Interventions for Chronic non-specific low back Pain. Eur Spine J. 2011; 20(1):19-39.

26. Matsubara T, Arai YP, Shimo K, Osuga Nishihara TM, Ushida T. Effects of Cognitive-behavioural therapy on pain Intensity and Level of Physical activity in Japaneses Patients with Chronic pain-A preliminary Quasi-experimental study. $J$ Phys Ther. 2010; 1:49-57.

27. Gatchel RJ, Rollings KH. Evidence informed management of chronic low back pain with cognitive behavioural therapy. Spine J. 2008; 8(1): 4044. 1 